\title{
Planned morning aerobic exercise in a fasted state increases energy intake in the preceding $24 \mathrm{~h}$
}

\author{
Asya Barutcu $^{1}$ (D) Elizabeth Briasco ${ }^{1} \cdot$ Jake Moon $^{1} \cdot$ David J. Stensel $^{1}$ (D) James A. King ${ }^{1}$ (D) Gemma L. Witcomb ${ }^{1}$ (D) \\ Lewis J. James ${ }^{1}$ iD
}

Received: 7 September 2020 / Accepted: 22 January 2021 / Published online: 23 February 2021

(c) The Author(s) 2021

\begin{abstract}
Purpose We previously observed increased energy intake (EI) at the meal before planned afternoon exercise, but the proximity of the meal to exercise might have reduced the scale of the pre-exercise anticipatory eating. Therefore, this study examined EI in the $24 \mathrm{~h}$ before fasted morning exercise.

Methods Fourteen males, experienced with gym-based aerobic exercise (age $25 \pm 5$ years, BMI $23.8 \pm 2.5 \mathrm{~kg} / \mathrm{m}^{2}$ ), completed counterbalanced exercise (EX) and resting (REST) trials. On day 1, subjects were told the following morning's activity (EX/ REST), before eating ad-libitum laboratory-based breakfast and lunch meals and a home-based afternoon/evening food pack. The following morning, subjects completed 30-min cycling and 30-min running (EX; 3274 $\pm 278 \mathrm{~kJ})$ or 60 -min supine rest (REST; $311 \pm 34 \mathrm{~kJ}$ ) fasted. Appetite was measured periodically, and EI quantified.

Results Afternoon/evening EI (EX $7371 \pm 2176 \mathrm{~kJ}$; REST $6437 \pm 2070 \mathrm{~kJ} ; P=0.017)$ and total 24-h EI (EX 14,055 $\pm 3672 \mathrm{~kJ}$; REST $12,718 \pm 3379 \mathrm{~kJ} ; P=0.011)$ were greater during EX, with no difference between trials at breakfast $(P=0.761)$ or lunch $(P=0.071)$. Relative EI (EI minus energy expended through EX/REST) was lower in EX $($ EX 10,781 $\pm 3539 \mathrm{~kJ} ; \mathrm{REST}$ $12,407 \pm 3385 \mathrm{~kJ} ; P=0.004)$.

Conclusion This study suggests planned fasted aerobic exercise increases EI during the preceding afternoon/evening, precipitating a $\sim 10 \%$ increase in EI in the preceding 24-h. However, this increase did not fully compensate for energy expended during exercise; meaning exercise induced an acute negative energy balance.
\end{abstract}

Keywords Appetite $\cdot$ Energy intake $\cdot$ Eating behavior $\cdot$ Weight loss $\cdot$ Exercise

\section{Introduction}

As the prevalence of overweight and obesity continues to rise globally, effective strategies to facilitate successful weight control are needed [1]. Prevention and management of obesity rely on the components of behaviour that influence energy balance, including physical activity [2]. In basic terms, energy balance is determined as energy intake (in consumed food and drink) minus energy expenditure (through metabolic processes and activity). Therefore, theoretically, individuals can either reduce energy consumed in food and drink or increase activity to disrupt energy balance and induce weight loss or prevent weight gain [3]. However,

Lewis J. James

L.James@lboro.ac.uk

1 School of Sport, Exercise and Health Sciences,

Loughborough University, Leicestershire LE11 3TU, UK in practice this interaction is very complex and influenced by a multitude of factors, making successful weight control difficult [4-6].

Aerobic exercise influences physiological components of appetite regulation [2, 7, 8]. A substantial amount of research has now been conducted on the acute effects of exercise on appetite and energy intake; generally reporting that acute aerobic exercise does not alter energy intake in the hours afterwards, compared to a resting control condition [9]. Although it is worth noting that research investigating higher exercise intensities (i.e. $>70 \% V_{2} \mathrm{O}_{2 \mathrm{xax}}$ ) consistently demonstrates a reduction in perceived hunger, but this does not always translate to similar changes in energy intake [10-13]. Therefore, in the acute setting, relative energy intake (energy consumed minus energy expended through exercise/rest) is reduced, resulting in a short term energy deficit [14]. In theory, this acute energy deficit should result in weight loss due to the disparity in energy balance. Many 
exercise intervention studies have tested this theory, in an attempt to induce weight loss (e.g. [15-19]). However, results from these studies have shown that there is considerable interindividual variability and the expected reductions in weight (calculated from exercise energy expenditure) are often not induced. Several mechanisms, such as compensatory increases in hunger/energy intake [20] and decreases in non-exercise physical activity [21] have been proposed to explain this response. However, evidence now suggests that non-exercise physical activity and resting metabolic rate are unaffected by exercise training [22], therefore shifting the focus towards the other side of the energy balance equation (i.e. energy intake).

Roughly 60 years ago, Jean Mayer suggested the concept that exercise induces compensatory increases in energy intake to restore energy balance [23]. This concept, however intuitive, is not consistent with short-term energy intake measurements made at meals consumed post-exercise, where exercise seems not to affect energy intake [9, 24]. Whilst exercise appears to induce changes in hormones secreted from the gastrointestinal tract (e.g. ghrelin, peptide tyrosine tyrosine, etc.), these endocrine alterations with exercise do not appear to influence energy intake, at least acutely [9]. More recently, studies have started to examine eating behaviour in the pre-exercise period [25-27]. In contrast to previous work examining energy intake after aerobic exercise, Barutcu, Witcomb and James [26] reported that when a post-exercise meal is planned in advance of aerobic exercise, energy intake was $\sim 24 \%$ greater than for planned rest. Similarly, other studies have shown that ad-libitum energy intake is increased when snack items [25] or meals [27] are provided before impending aerobic exercise compared to resting conditions.

One consideration with these previous studies is that the proximity of the pre-exercise snack/meal to the exercise session may have tempered the responses observed [25, 27]. Given the short time interval between the pre-exercise meal and the exercise session ( $1-3 \mathrm{~h}$ ) in these previous studies $[25,27]$, it is possible that subjects individual considerations about the effect of food intake on gastrointestinal comfort during exercise may have influenced their desire/motivation to increase energy intake. Although many exercise sessions will take place in the immediate post-prandial period, many will not, including sessions taking place after an overnight fast. Therefore, this study investigated the effect of an anticipated exercise session in the morning after a $>9 \mathrm{~h}$ fast (to remove any potential effects of proximity of exercise to meals on eating behaviour) on appetite and energy intake in the preceding $24 \mathrm{~h}$ and compared these responses to an identical resting control trial. It was hypothesised that energy intake over the afternoon/evening meal, and perhaps lunch (given the results from our previous work), but not breakfast, would be greater before exercise compared to rest.

\section{Methods}

\section{Subjects}

Subjects were fourteen healthy, non-smoking, weight stable (self-reported), and habitually active $(<10 \mathrm{~h}$ per week) males, (age $25 \pm 5$ years; BMI $23.8 \pm 2.5 \mathrm{~kg} / \mathrm{m}^{2}$; body fat $\%$

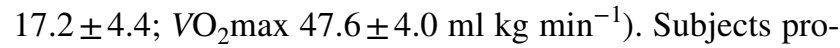
vided written consent before completing the study. Ethical approval was obtained from the Loughborough University Ethics Approvals (Human Participants) Sub Committee (reference number: R17-P133), but as this was not a clinical trial, it was not pre-registered on a clinical trials database. Subjects were not taking any medications known to affect appetite, and were also not restricted, disinhibited, or hungry eaters (i.e. not in the clinical range), as determined by the Three-Factor Eating Questionnaire [28]. Each subject completed two preliminary trials and two experimental trials in a randomised counterbalanced order. Using the data from a previous study from our laboratory [27], an alpha of 0.05 , a beta of 0.8 and a between trial correlation of 0.8 , it was determined that 14 subjects would be required to detect a $15 \%$ difference in total $24 \mathrm{~h}$ energy intake between trials.

\section{Pre-trial standardisation}

In the $24 \mathrm{~h}$ preceding the first experimental trial, subjects recorded their dietary intake and physical activity. These diet and activity patterns were replicated before the second experimental trial and adherence to these requirements was verbally confirmed before trials. Strenuous exercise and alcohol intake were also not permitted during this period.

\section{Preliminary trials}

Subjects completed two preliminary trials. During the first trial, which took place at a time convenient for the subject, height (to nearest $0.1 \mathrm{~cm}$; SECA stadiometer, Germany), and body mass (to nearest $0.01 \mathrm{~kg}$; Adam Equipment, CFM150 scales, UK) were measured. Subcutaneous body fat was estimated from skinfold measurements at four sites (biceps, triceps, supra-iliac, sub-scapula) using callipers using callipers (Harpenden, UK). The sum of all four sites were used to estimate body density [29] and percentage of body fat [30]. Subjects also completed questionnaires to assess health status and eating patterns and performed two submaximal tests: one on a cycle ergometer (Lode Corival, Groningen, Holland) and one on a motorised treadmill $(\mathrm{h} / \mathrm{p} / \mathrm{cosmos}$ sports and medical $\mathrm{GmbH} /$ Munich, Germany). Sub-maximal tests involved four, 4-min stages of workloads between 80 and $280 \mathrm{~W}$ (cycle ergometer) and 6-13 km/h (treadmill), with 
each stage separated by a short rest period. At the end of each stage, heart rate (Polar M400, Kempele, Finland) and rating of perceived exertion (RPE) [31] were recorded.

After a short break, subjects then completed a maximal incremental exercise test to exhaustion $\left(\mathrm{VO}_{2}\right.$ peak) on the treadmill, commencing at a gradient of $1 \%$ and at a speed estimated to elicit a heart rate of $\sim 160$ beats $/ \mathrm{min}$. The gradient increased by $1 \%$ every minute until volitional exhaustion. Expired gas was collected during the final minute of this maximal incremental exercise test and heart rate and RPE were recorded every minute. Intensities for the exercise session during experimental trials were derived from the heart rate-exercise intensity relationship determined in the sub-maximal stages, as well as the peak heart rate reached during the $\mathrm{VO}_{2}$ peak test.

During the second preliminary trial, subjects arrived at the laboratory at $0800 \mathrm{~h}$ and were asked to complete a visual analogue scale for subjective appetite ratings (detailed below). Subjects then started the exercise session in a fasted state to ensure they were experienced with the specific exercise session and the laboratory environment. The exercise session involved a total of $60 \mathrm{~min}$ exercise (30 min cycling and 30 min running), as described in the exercise trial. An ad-libitum buffet breakfast was served 30-min post-exercise, and subjects were free to leave after this period. Visual analogue scales were completed throughout the day. Three hours post-breakfast, subjects arrived back at the laboratory for lunch and were provided with visual analogue scales for the rest of the day, as well as an afternoon/evening food pack. Subjects were not allowed to eat for $2 \mathrm{~h}$ post-lunch and after $2300 \mathrm{~h}$ in the evening.

\section{Experimental trials}

Subjects completed two, 2-day experimental trials; exercise (EX) and rest (REST) in a randomised counter-balanced order and separated by at least 4 days.

On day 1 , subjects arrived at the laboratory at $0800 \mathrm{~h}$ for breakfast. A baseline appetite questionnaire was completed upon arrival $(0800 \mathrm{~h})$ and post-void body mass was recorded in light clothing. Subjects were then told if they were on the EX or REST trial (i.e. what they would do the following morning) and given $30 \mathrm{~min}$ to consume breakfast (0800-0830 h) from a selection of cold ready-to-eat foods. Upon completion of breakfast, subjects completed another appetite questionnaire $(0830 \mathrm{~h})$ and left the laboratory, before returning at $1200 \mathrm{~h}$ for lunch. Lunch was served for $30 \mathrm{~min}$ and consisted of a buffet selection of ready-to-eat cold foods. Appetite questionnaires were completed before and after lunch. After lunch, subjects were provided with a food pack containing a main evening meal and a selection of snack items from which they were free to consume during the afternoon/evening period. The entire food pack (including all empty wrappers) was returned to the laboratory the following morning. Standard instructions were read to subjects before the breakfast and lunch buffet meals on day 1 . These were as follows: "You have $30 \mathrm{~min}$ to have your breakfast. Remember that you are on the EX/REST trial tomorrow, so please choose your food items accordingly. You are welcome to eat whatever and however much you want from the selection. If you want more of anything, please let the researchers know and we will put out more food". For the evening meal "You are not allowed to eat anything for $2 \mathrm{~h}$ after lunch, after this time you are free to eat whatever and however much you want from the food pack provided until $2300 \mathrm{~h}$. You are not allowed anything else that is not in the pack apart from water. When you're ready to have your pasta meal, please use the bowl provided and put any leftovers back in the Tupperware box. Please keep all wrappers and fruit skins and return everything the next day".

On day 2, subjects returned to the laboratory at $0800 \mathrm{~h}$ and completed another appetite questionnaire, before postvoid body mass was again measured, and they completed the 60-min exercise/rest. In the EX trial, exercise consisted of 30 min of steady-state cycling at a workload equal to $75 \%$ HR-max and 30 min of steady state running at a running speed equal to $\sim 80 \%$ HR-max. Heart rate was recorded every 5 min and RPE was recorded every 15 min during exercise. Expired gas samples were collected between 14-15 min and 29-30 min during cycling and running. All expired gas samples collected in experimental trials were analysed for oxygen and carbon dioxide concentration (Servomex 1440, Crowborough, UK), volume (Harvard Dry Gas Meter, Harvard Ltd, Edenbridge, UK) and temperature (Edale, Cambridge, UK). Ambient room air was analysed concurrent with expired gas collections to correct $V_{2}$ and $V \mathrm{CO}_{2}$ values [32].

For the REST trial, day 1 was the same as described above. On day 2, instead of completing the exercise session, subjects rested on a portable bed in a supine position for $60 \mathrm{~min}$, with expired gas samples collected at 25-30 min and 55-60 min.

\section{Study foods}

For all meals, foods were provided in excess of expected consumption. Breakfast and lunch were multi-item buffet meals, consisting of cold ready-to-eat foods, which were presented in a research kitchen (Table 1). Subjects chose foods from the buffet and ate in isolation in a separate dining room, returning to the buffet as many times as they desired during each 30-min meal period. For both breakfast and lunch, the amount consumed was quantified by weighing the food before and after consumption, with macronutrient content of foods ascertained from manufacturer values. 
Table 1 Items provided at each meal

\begin{tabular}{|c|c|c|}
\hline \multicolumn{3}{|l|}{ Breakfast buffet items } \\
\hline White bread & Cornflakes-cereal & Peanut butter spread \\
\hline Brown bread & Weetabix-cereal & Nutella spread \\
\hline Rice Krispies-cereal & Strawberry yoghurt & Strawberry jam spread \\
\hline Crunchy nut—cereal & Raspberry yoghurt & Bananas \\
\hline Shreddies-cereal & Cherry yoghurt & Apples \\
\hline Coco pops-cereal & Apple juice & Clementines \\
\hline Cheerios-cereal & Orange juice & Milk \\
\hline \multicolumn{3}{|l|}{ Lunch buffet items } \\
\hline White bread & Cherry yoghurt & Salt and vinegar crisps \\
\hline Brown bread & Strawberry yoghurt & Cheese and onion crisps \\
\hline Mature cheddar cheese & Raspberry yoghurt & Orange squash \\
\hline Honey smoked ham & Cadbury mini rolls & Summer fruits squash \\
\hline Grilled chicken pieces & Mayonnaise & Apples \\
\hline Can of tuna & Butter & Clementines \\
\hline Lettuce & Chocolate chip cookies & \\
\hline Tomatoes & Salted crisps & \\
\hline \multicolumn{3}{|l|}{ Evening meal } \\
\hline Nutri-grain apple cereal bar & Mini cookies & Clementines \\
\hline Nutri-grain blueberry cereal bar & Salted crisps & Bananas \\
\hline Nutri-grain strawberry cereal bar & Salt and vinegar crisps & Strawberry yoghurt \\
\hline Mars chocolate—fun size & Cheese and onion crisps & Cherry yoghurt \\
\hline Twix chocolate—fun size & Prawn cocktail crisp & Raspberry yoghurt \\
\hline Maltesers chocolate-fun size & Apples & Tomato pasta meal \\
\hline
\end{tabular}

The afternoon/evening food pack contained a homogenous cheese and tomato pasta meal $\left(6.60 \pm 0.05 \mathrm{~kJ} \mathrm{~g}^{-1}\right.$, with $14 \%, 60 \%, 25 \%$ and $1 \%$ of the energy provided by protein, carbohydrate, fat and fibre, respectively) prepared in a standard manner the day before the experimental trial and given to the subjects cold. Additional food consisting of a selection of confectionary snacks, cereal bars, crisps, yogurts, etc. (Table 1) were supplied in the pack. Subjects were free to consume what they wanted from the food pack at any time between 1430 and $2300 \mathrm{~h}$. The pack, as well as any empty wrappers, Tupperware, fruit skins/cores and leftovers were returned the following morning. Energy intake was determined by weighing food items before and after they were returned the next day, with macronutrient content of foods ascertained from manufacturer values. Food was not allowed in the $2 \mathrm{~h}$ post-lunch and after $2300 \mathrm{~h}$.

\section{Subjective appetite sensations}

Subjects rated their feelings of hunger 'How hungry do you feel?', fullness 'How full do you feel?', desire to eat (DTE) 'How strong is your desire to eat?', and prospective food consumption (PFC) 'How much food do you think you could eat?' on $100 \mathrm{~mm}$ visual analogue scales throughout the day [33]. Verbal anchors of 'not at all'/'none at all'/'no desire at all' and 'extremely'/'a lot' were placed at 0 and $100 \mathrm{~mm}$, respectively. Appetite was rated at 0800 upon arrival at the lab on both days, as well as before and after each meal and before bed on day 1, and at the mid-point and end of exercise/rest on day 2 .

\section{Statistical analysis}

Data were analysed using SPSS 23.0 (SPSS Inc., Somers, NY, USA). All data were checked for normality of distribution using a Shapiro-Wilk test. Data containing one factor were analysed using a $t$ test or Wilcoxon signed-rank test, as appropriate. Data containing two factors were analysed using a two-way repeated measures ANOVA and, where appropriate, followed by Bonferroni-adjusted paired $t$ tests or Bonferroni-adjusted Wilcoxon signed-rank tests, as appropriate. Data sets were determined to be significantly different when $P \leq 0.05$. Data are presented as mean \pm standard deviation throughout, unless otherwise stated.

\section{Results}

\section{Pre-trial measures}

Pre-trial (i.e. day 1) body mass (EX $78.7 \pm 6.5 \mathrm{~kg}$; REST $78.4 \pm 6.7 \mathrm{~kg} ; t=1.193 ; d f=13 ; P=0.254)$, hunger 
$(Z=-0.534 ; P=0.594)$, fullness $(Z=-0.196 ; P=0.844)$, DTE $(t=0.582 ; d f=13 ; P=0.571)$ and PFC $(t=0.583$; $d f=13 ; P=0.570)$ did not differ between trials.

\section{Energy and macronutrient intake}

On day 1 , energy intake at breakfast $(Z=-0.345 ; P=0.761)$ and lunch $(t=1.964 ; d f=13 ; P=0.071)$ were not different between trials, although the data for lunch approached significance. However, energy intake over the evening was $\sim 930 \mathrm{~kJ}(\sim 13 \%)$ greater in EX compared to REST ( $t=2.723 ; d f=13 ; P=0.017$ ) (Table 2; Fig. 1). Total 24-h energy intake on day 1 was $\sim 1340 \mathrm{~kJ}(\sim 10 \%)$ greater in EX compared to REST $(t=2.966 ; d f=13 ; P=0.011)$ (Table 2;

Fig. 2).
On day 2 , energy expenditure during the 60-min exercise/rest session was $2960 \mathrm{~kJ}$ greater during EX (EX $3274 \pm 278 \mathrm{~kJ} ; \operatorname{REST} 311 \pm 34 \mathrm{~kJ} ; t=38.887 ; d f=13$; $P<0.001)$ and, therefore, relative energy intake (energy intake on day 1 minus energy expended during exercise/ rest) was less in $\mathrm{EX}(t=-3.451 ; d f=13 ; P=0.004)$.

Regarding macronutrient intakes, protein intake was greater in EX at lunch $(t=2.228 ; d f=13 ; P=0.044)$, whilst intake of all macronutrients was greater in EX the afternoon/evening $(P \leq 0.042)$. Over the 24 -h pre-exercise, intakes of carbohydrate $(+10 \% ; P=0.025)$, protein $(+9 \%$; $P=0.017)$ and fat $(+11 \% ; P=0.005)$ were all greater in EX (Table 2).
Table 2 Total energy (kJ), carbohydrate $(\mathrm{CHO})$, protein (PRO), fat, and fibre intakes on day 1 for each meal during both trials
Fig. 1 Breakfast, lunch and evening meal energy intakes during both trials. Values are mean $\pm \mathrm{SD}$. Lines that intersect the EX and REST bars represent individual data. ${ }^{\dagger}$ Indicates values significantly different to REST $(P<0.05)$

\begin{tabular}{llllcc}
\hline & Total energy $(\mathrm{kJ})$ & CHO $(\mathrm{g})$ & PRO $(\mathrm{g})$ & FAT $(\mathrm{g})$ & Fibre $(\mathrm{g})$ \\
\hline Breakfast & & & & & \\
EX & $3358 \pm 1254$ & $129.9 \pm 47.2$ & $26.6 \pm 10.3$ & $17.7 \pm 12.1$ & $8.6 \pm 4.2$ \\
REST & $3248 \pm 1337$ & $126.6 \pm 41.8$ & $26.4 \pm 10.9$ & $16.5 \pm 13.0$ & $8.1 \pm 4.6$ \\
Lunch & & & & \\
EX & $3326 \pm 817$ & $71.3 \pm 19.8$ & $45.4 \pm 15.7^{\mathrm{a}}$ & $34.7 \pm 14.7$ & $7.7 \pm 2.0$ \\
REST & $3033 \pm 803$ & $63.3 \pm 22.3$ & $42.0 \pm 14.8$ & $32.2 \pm 12.6$ & $7.1 \pm 2.1$ \\
Afternoon/evening period & & & & \\
EX & $7371 \pm 2176^{\mathrm{a}}$ & $258.8 \pm 77.4^{\mathrm{a}}$ & $47.2 \pm 11.7^{\mathrm{a}}$ & $55.2 \pm 20.1^{\mathrm{a}}$ & $11.1 \pm 4.2^{\mathrm{a}}$ \\
REST & $6437 \pm 2070$ & $228.1 \pm 71.7$ & $40.9 \pm 11.2$ & $47.8 \pm 18.4$ & $9.9 \pm 3.9$ \\
Total 24 h & & & & & \\
EX & $14,055 \pm 3672^{\mathrm{a}}$ & $460.0 \pm 125.3^{\mathrm{a}}$ & $119.4 \pm 23.9^{\mathrm{a}}$ & $107.6 \pm 36.4^{\mathrm{a}}$ & $27.4 \pm 8.2$ \\
REST & $12,718 \pm 3379$ & $418.0 \pm 104.4$ & $109.3 \pm 23.0$ & $96.5 \pm 36.6$ & $25.1 \pm 6.5$ \\
\hline
\end{tabular}

Data are mean $\pm \mathrm{SD}$

${ }^{a}$ Indicates values significantly different to REST $(P<0.05)$. Please note that the evening pasta meal was homogenous in nature; therefore; macronutrient intake is proportional to volume consumed

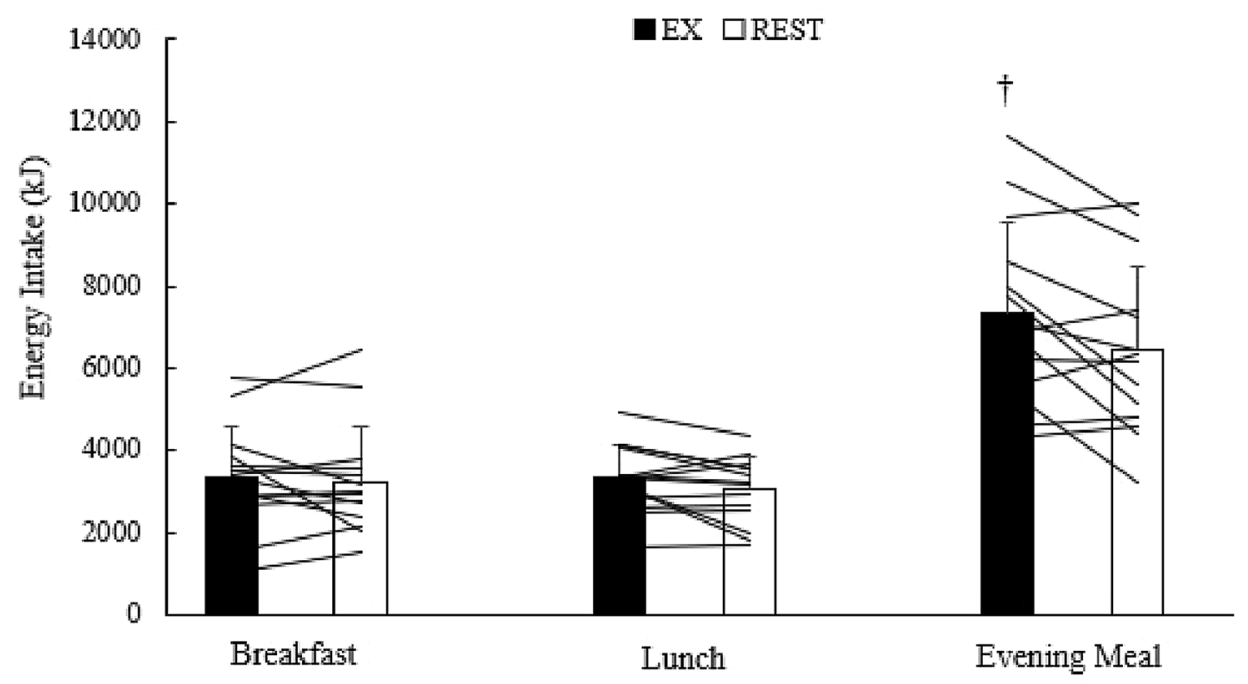


Fig. 2 Total energy intake and Relative energy intake values for both trials. Values are mean $\pm \mathrm{SD}$. Lines that intersect the EX and REST bars represent individual data. ${ }^{\dagger}$ Indicates values significantly different to REST $(P<0.05)$

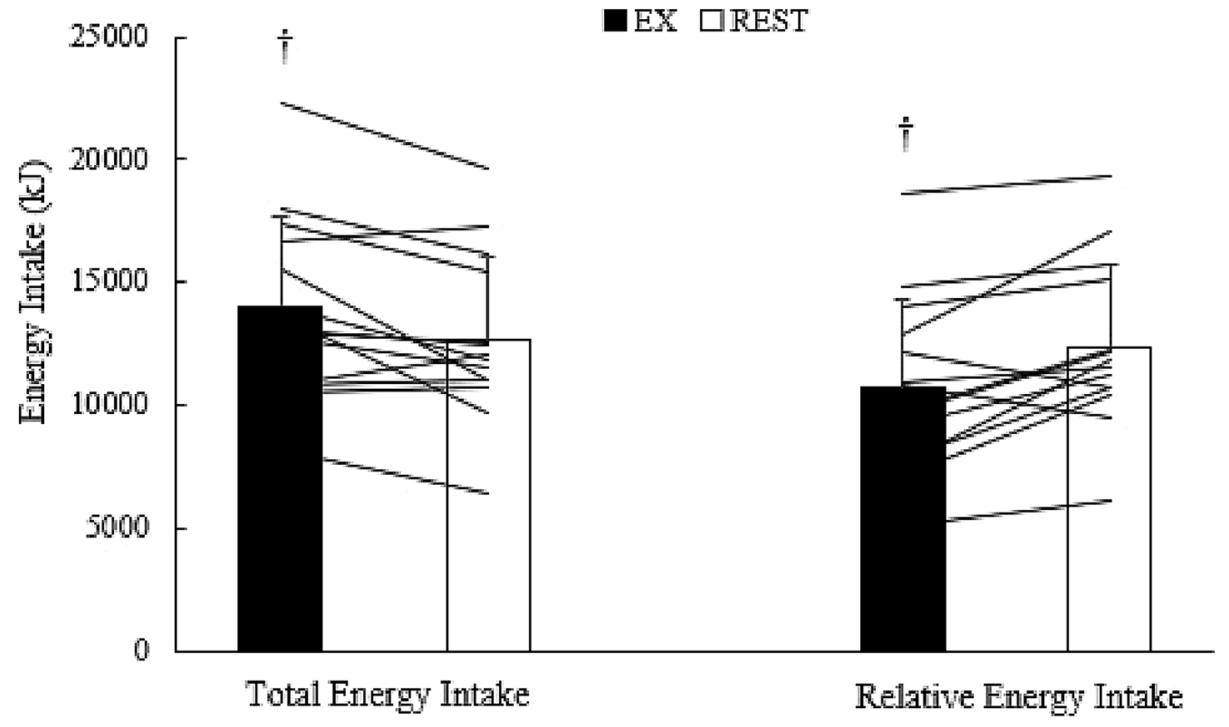

Table $3 V_{2}$, RER, heart rate and RPE during EX and REST trials

\begin{tabular}{lllll}
\hline & $V \mathrm{O}_{2}(\mathrm{~L} / \mathrm{min})$ & $\mathrm{RER}$ & Heart rate $(\mathrm{bpm})$ & $\mathrm{RPE}$ \\
\hline EX & $2.51 \pm 0.213^{\mathrm{a}}$ & $0.95 \pm 0.033^{\mathrm{a}}$ & $143 \pm 21$ & $13 \pm 1$ \\
REST & $0.25 \pm 0.003$ & $0.85 \pm 0.03$ & N/A & N/A \\
\hline
\end{tabular}

Data are mean \pm SD

${ }^{a}$ Indicates values significantly different to REST $(P<0.05)$

\section{Steady state exercise measures}

All mean steady state values (HR, RPE, $V \mathrm{O}_{2}, \mathrm{RER}$ ) are presented in Table 3. $V \mathrm{O}_{2}(t=34.751 ; d f=13 ; P<0.0001)$ and RER $(t=3.120 ; d f=13 ; P=0.009)$ were greater during EX.

\section{Subjective appetite sensations}

There were main trial effects for hunger $(F(d f=1)=13.257$; $P=0.003)$, desire to eat $(F(1)=14.060 ; P=0.002)$ and prospective food consumption $(F(d f=1)=7.338 ; P=0.018)$, but not fullness $(F(d f=1)=3.606 ; P=0.080)$. There were no time $\times$ trial interaction effects for any of the subjective appetite ratings (hunger: $F(d f=4.485)=2.217$; $P=0.071$; fullness: $F(d f=3.914)=1.039 ; P=0.396$; DTE: $F(d f=4.416)=1.942 ; P=0.109$; PFC: $F(d f=4.526)=1.238$; $P=0.304$; Fig. 3). There were main effects of time for all subjective appetite ratings $(P<0.001)$.

\section{Discussion}

This study investigated the effect of an anticipated morning-fasted aerobic exercise session on appetite and energy intake in the $24 \mathrm{~h}$ before exercise, compared to an identical resting control trial. It was hypothesised that energy intake over the afternoon/evening, and potentially at lunch, but not at breakfast, would be greater for exercise compared to rest. In line with this hypothesis, energy intake during the afternoon/evening was $~ 13 \%$ greater in EX compared to REST, whilst energy intake at breakfast and lunch were not significantly different between trials.

These results are consistent with the findings of two previous studies that have examined eating behaviour at meals served before known exercise sessions [25, 27]. Results from most previous studies investigating the effects of acute exercise on appetite and energy intake suggest that energy intake after exercise is no different to after a similar period of rest $[9,10]$. Interestingly, aerobic exercise appears to produce endocrine effects that one might hypothesise would decrease post-exercise energy intake. Exercise decreases concentrations of acylated ghrelin [34, 35] and increases concentrations of peptide tyrosine tyrosine (PYY) [36]. These effects should, in theory, result in reduced appetite and energy intake at the subsequent meal according to ghrelin's orexigenic [37] and PYY's anorexigenic characteristics [38]. Whilst reductions in subjective appetite are commonly reported during or immediately after exercise [39, 40], these reductions are usually corrected shortly after exercise has ceased and before eating, but endocrine alterations can persist [41]. Whilst aerobic exercise does, on the whole, produce weight loss, the typical weight loss observed is far from what would be predicted on the basis of the energy deficit created by acute studies [42-44]. In the present study, exercise still reduced relative energy intake, but the increase in pre-exercise energy intake was sufficient to compensate for $\sim 45 \%$ of the energy deficit created. This is a substantial compensation and might, at least partially, account for the less 

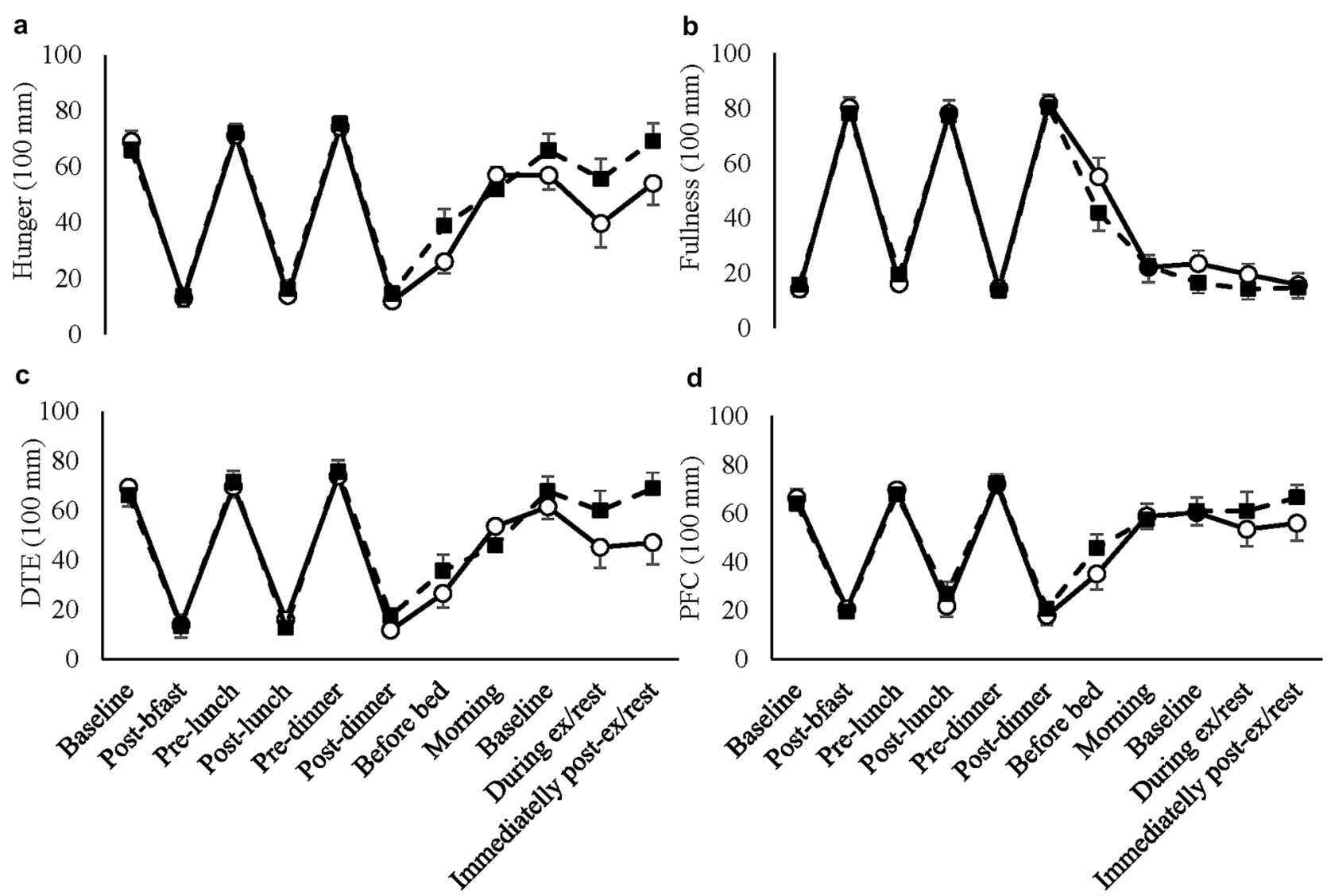

Fig. 3 Hunger (a), fullness (b), DTE (c) and PFC (d) ratings for day 1. The solid line presents EX and dotted line presents REST trial. Values are mean \pm SEM. ${ }^{\dagger}$ Indicates significance

than expected weight loss observed in previous exercise training studies.

This eating behaviour has also been observed in another recent study that investigated the effects of a future exercise session on pre-exercise energy intake in sedentary overweight males [25]. In this study, subjects (restrained and unrestrained) were provided with a standardised breakfast and lunch followed by an ad-libitum snack (potato chips) 60-min before a known exercise or rest session. Unlike the present study, where all subjects completed a standardised 60-min aerobic exercise session, subjects were instructed to complete an exercise session until they considered they had completed a "sufficient workout". This study reported that restrained eaters consumed significantly more $(\sim 677 \mathrm{~kJ})$ before the exercise trial compared to a resting trial: however, this effect was not present with the unrestrained eaters. In contrast to the results from Sim et al. [25], the present study observed that unrestrained eaters increased their energy intake by $\sim 1337 \mathrm{~kJ}$ the day before a morning exercise session. This may be explained by the differences in eating opportunities provided, as in the current study subjects had access to ad-libitum breakfast, lunch and evening meals in the $24 \mathrm{~h}$ pre-exercise, consisting of a variety of food items, whereas, Sim et al. [25] provided only one ad-libitum eating opportunity $60 \mathrm{~min}$ before exercise, with only one food option (potato chips). Furthermore, given that the subjects of Sim et al. [25] were sedentary individuals, as opposed to the regular exercisers in the present study, their lack of experience with exercise training may have reduced their tendency to supplement their energy intake in anticipation of exercise.

In this context, there is evidence to suggest that responses for energy intake in the hours after exercise are different between active and inactive individuals [9]. According to the meta-analysis of Schubert et al. [9], the absolute energy intake values obtained after an exercise session indicated that individuals who engaged in lower levels of physical activity or exercise were more receptive to the appetite suppressing effects of exercise. This is also supported by the work of Jokisch et al. [45] and Mayer and Thomas [46]. These studies suggest that there may be some conditioning, whereby regular exercisers may learn to increase their energy intake around exercise over time. Given that expected satiety/satiation characteristics of a food are strong predictors of portion size selection, 
which are also learnt from previous experiences [47-49], it could be argued that decisions about food intake in close temporal proximity to exercise may also be influenced by previous experiences of exercise (specifically energy expenditure). Speculatively, this conditioning might play a part in determining a portion size in the hours before (or indeed after) an exercise session. In line with this, McCaig et al. [50] observed that subjects increased energy intake at the subsequent test meal when they were informed that they had expended $\sim 1110 \mathrm{~kJ}$, compared to a group who were informed that they expended $\sim 210 \mathrm{~kJ}$. Indeed, the study of McCaig et al. [50] adds weight to the hypothesis that the anticipation of an exercise session, or energy expenditure per se, may influence decisions about meal planning, and subsequently portion size/food consumption. Taken together, and whilst speculative, results from these studies may clarify some of the less than expected weight loss observed in chronic exercise intervention studies [51] and future studies should examine this element of eating behaviour in chronic exercise training studies.

Other possible mechanisms that could explain the results from this study could be the Compensatory Health Beliefs Model [52]. The Compensatory Health Beliefs Model suggests that certain unhealthy behaviours (i.e. having extra energy/food) can be compensated for by engaging in positive, healthy behaviours (such as exercise) [52, 53]. This model could partially explain the results of the present study as the subjects may have justified, to themselves, that the upcoming exercise session provided them with the 'license' to eat more food in advance of the exercise. Initially, we observed this behaviour in our previous work [27] where compensation occurred only at the preceding mealtime before exercise, however we were uncertain how far in advance this compensatory behaviour would come into effect given the lack of research in this area. The prospect of completing a 60-min aerobic exercise session after a $>9 \mathrm{~h}$ fast may have also encouraged subjects to consume more during the evening meal in the hope that they would have enough energy available to carry out the task. Additionally, recommendations given to athletes suggest increasing energy, especially carbohydrate, intake in the hours before exercise [54]. However, given that such recommendations for athletes infiltrate into lay publications (e.g. magazines and online resources), regular exercisers may develop the view that they too should also increase their energy intake. Energy intake was only increased in EX in the afternoon/ evening, which combined with our previous work [27], suggests that it may only be the meal that immediately precedes exercise where additional energy is ingested. Future work should focus on exploring these effects over multiple sessions, as well as exploring the interaction between pre-and post-exercise energy compensation in situations were individuals are exercising on a regular (perhaps daily) basis, as in this setting one sessions post-exercise nutrition may also be the next session's pre-exercise nutrition.

It appears, from the results of this and previous studies [25-27], that when exercisers make decisions about food intake in advance of an impending exercise session, their energy intake/portion size might be increased. Clearly the weight status or, perhaps more importantly, the weight management goals of the subjects might have played a part in their decision (conscious or unconscious) to increase energy intake in advance of exercise. The subjects in the present study were weight stable, not trying to lose weight, and habitually physically active. Therefore, they would be achieving energy balance on a day-to-day basis, meaning it is logical that they would increase their energy intake where energy expenditure is increased. Thus, it would be of great importance to understand whether this phenomenon of increasing energy intake in anticipation of an exercise session is apparent in overweight/obese populations where weight loss is a goal, and this should be the focus of future work in this area. What accounts for this effect is not known and should be the focus of future studies as it may help to reduce compensatory eating and strengthen the energy deficit created by exercise. Although speculative, it would be interesting to know if it was caused by a 'licencing effect', where individuals might have perceived the impending energy expenditure through exercise to licence them to increase their EI.

In conclusion, this study demonstrates that anticipation of fasted, morning aerobic exercise may cause individuals to increase their energy intake the evening before. Whilst this increase in pre-exercise energy intake compensated for $45 \%$ of the energy deficit created by exercise, the exercise session still produced an acute negative energy balance. The results from this study better our understanding of the relationship between exercise and energy intake/balance and suggest a potential time period where those engaged with chronic exercise training might increase their energy intake. These results might help to explain, at least partially, why aerobic exercise training studies often do not observe the anticipated weight loss with training. Long-term exercise studies that employ inactive individuals might go some way to explaining the mechanisms and timescales behind this phenomenon.

Funding This research was partially supported by the National Institute for Health Research Leicester Biomedical Research Centre. This report is independent research by the National Institute for Health Research. The views expressed in this publication are those of the authors and not necessarily those of the NHS, the National Institute for Health Research or the Department of Health.

\section{Compliance with ethical standards}

Conflict of interest LJJ has received funding for research from and/ or acted as a consultant for Decathlon SA, the Collagen Research In- 
stitute, PepsiCo, Inc., Volac International Ltd, British Summer Fruits, Lucozade Ribena Suntory and Progressive Sports Technologies. LJJ has also received funding to attend conferences from GSSI and Danone Nutricia. In all cases, no personal payments were received by LJJ.

Open Access This article is licensed under a Creative Commons Attribution 4.0 International License, which permits use, sharing, adaptation, distribution and reproduction in any medium or format, as long as you give appropriate credit to the original author(s) and the source, provide a link to the Creative Commons licence, and indicate if changes were made. The images or other third party material in this article are included in the article's Creative Commons licence, unless indicated otherwise in a credit line to the material. If material is not included in the article's Creative Commons licence and your intended use is not permitted by statutory regulation or exceeds the permitted use, you will need to obtain permission directly from the copyright holder. To view a copy of this licence, visit http://creativecommons.org/licenses/by/4.0/.

\section{References}

1. Abarca-Gómez L, Abdeen ZA, Hamid ZA, Abu-Rmeileh NM, Acosta-Cazares B, Acuin C et al (2017) Worldwide trends in body-mass index, underweight, overweight, and obesity from 1975 to 2016: a pooled analysis of 2416 population-based measurement studies in 128.9 million children, adolescents, and adults. Lancet 390(10113):2627-2642

2. Blundell JE, Gibbons C, Caudwell P, Finlayson G, Hopkins M (2015) Appetite control and energy balance: Impact of exercise. Obes Rev 16(S1):67-76

3. Lean MEJ, Astrup A, Roberts SB (2018) Making progress on the global crisis of obesity and weight management. BMJ 13(361):k2538

4. Casazza K, Fontaine KR, Astrup A, Birch LL, Brown AW, Bohan Brown MM et al (2013) Myths, presumptions, and facts about obesity. N Engl J Med 368(5):446-454

5. Fogelholm M, Kukkonen-Harjula K (2000) Does physical activity prevent weight gain: a systematic review. Obes Rev 1(2):95-111

6. Blundell JE (2017) The contribution of behavioural science to nutrition: appetite control. Nutr Bull 42(3):236-245

7. King JA, Wasse LK, Ewens J, Crystallis K, Emmanuel J, Batterham RL et al (2011) Differential acylated ghrelin, peptide YY3-36, appetite, and food intake responses to equivalent energy deficits created by exercise and food restriction. J Clin Endocrinol Metab 96(4):1114-1121

8. Nassis GP, Klentrou P, Palmeira A, Stensel DJ (2012) The influence of physical activity on obesity and health. J Obes 2012:1-2

9. Schubert MM, Desbrow B, Sabapathy S, Leveritt M (2013) Acute exercise and subsequent energy intake. A meta-analysis. Appetite 63:92-104

10. Imbeault P, Saint-Pierre S, Alméras N, Tremblay A (1997) Acute effects of exercise on energy intake and feeding behaviour. $\mathrm{Br} \mathrm{J}$ Nutr 77(4):511-521

11. Lluch A, King NA, Blundell JE (2000) No energy compensation at the meal following exercise in dietary restrained and unrestrained women. Br J Nutr 84:219-225

12. Pomerleau M, Imbeault P, Parker T, Doucet E (2004) Effects of exercise intensity on food intake and appetite in women. Am J Clin Nutr 80(5):1230-1236

13. Broom DR, Batterham RL, King JA, Stensel DJ, Stensel DJ (2009) Influence of resistance and aerobic exercise on hunger, circulating levels of acylated ghrelin, and peptide YY in healthy males. Am J Physiol Integr Comp Physiol 296:29-35
14. Caudwell P, Gibbons C, Hopkins M, Naslund E, King N, Finlayson $\mathrm{G}$ et al (2011) The influence of physical activity on appetite control: an experimental system to understand the relationship between exercise-induced energy expenditure and energy intake. Proc Nutr Soc 70(2):171-180

15. King NA, Hopkins M, Caudwell P, Stubbs RJ, Blundell JE (2008) Individual variability following 12 weeks of supervised exercise: identification and characterization of compensation for exerciseinduced weight loss. Int J Obes 32(1):177-184

16. Wu T, Gao X, Chen M, van Dam RM (2009) Long-term effectiveness of diet-plus-exercise interventions vs. diet-only interventions for weight loss: a meta-analysis. Obes Rev 10(3):313-323

17. Thorogood A, Mottillo S, Shimony A, Filion KB, Joseph L, Genest J et al (2011) Isolated aerobic exercise and weight loss: a systematic review and meta-analysis of randomized controlled trials. Am J Med 124(8):747-755

18. Foster-Schubert KE, Alfano CM, Duggan CR, Xiao L, Campbell KL, Kong A et al (2012) Effect of diet and exercise, alone or combined, on weight and body composition in overweight-to-obese postmenopausal women. Obesity 20(8):1628-1638

19. Johns DJ, Hartmann-Boyce J, Jebb SA, Aveyard P (2014) Diet or exercise interventions vs combined behavioral weight management programs: a systematic review and meta-analysis of directcom parisons. J Acad Nutr Diet 114(10):1557-1568

20. Hopkins M, King NA, Blundell JE (2010) Acute and long-term effects of exercise on appetite control: is there any benefit for weight control? Curr Opin Clin Nutr Metab Care 13(6):635-640

21. Kozey-Keadle S, Staudenmayer J, Libertine A, Mavilia M, Lyden $\mathrm{K}$, Braun B et al (2014) Changes in sedentary time and physical activity in response to an exercise training and/or lifestyle intervention. J Phys Act Health 11(7):1324-1333

22. Fedewa MV, Hathaway ED, Williams TD, Schmidt MD (2017) Effect of exercise training on non-exercise physical activity: a systematic review and meta-analysis of randomized controlled trials. Sport Med 47(6):1171-1182

23. Mayer J, Roy P, Kamakiiya A, Mitra P (1956) Relation between caloric intake, body weight, and physical work: studies in an industrial male population in West Bengal. Am J Clin Nutr $4(2): 169-175$

24. Dorling J, Broom DR, Burns SF, Clayton DJ, Deighton K, James LJ et al (2018) Acute and chronic effects of exercise on appetite, energy intake, and appetite-related hormones: the modulating effect of adiposity, sex, and habitual physical activity. Nutrients 10(9):1140

25. Sim AY, Lee LL, Cheon BK (2018) When exercise does not pay: counterproductive effects of impending exercise on energy intake among restrained eaters. Appetite 123:120-127

26. Barutcu A, Witcomb GL, James LJ (2019) Anticipation of aerobic exercise increases planned energy intake for a post-exercise meal. Appetite 138:198-203

27. Barutcu A, Taylor S, McLeod CJCJ, Witcomb GLGL, James LJ (2020) Planned aerobic exercise increases energy intake at the preceding meal. Med Sci Sport Exerc 52(4):968-975

28. Stunkard A, Messick S (1985) The three-factor eating questionnaire to measure dietary restraint, dishinbition and hunger. J Psychosom Res 29(I):71-83

29. Durnin JV, Womersley J (1973) Body fat assessed from total body density and its estimation from skinfold thickness: measurements on 481 men and women aged from 16 to 72 years. Br J Nutr. 32(1):77-97

30. Siri WE (1956) The gross composition of the body. Adv Biol Med Phys 1(4):239-280

31. Borg A (1982) Psychophysical bases of perceived exertion. Med Sci Sport Exerc 14(5):377-381

32. Betts JA, Thompson D (2012) Thinking outside the bag (not necessarily outside the lab). Med Sci Sports Exerc 44(10):2040 
33. Flint A, Raben A, Blundell JE, Astrup A (2000) Reproducibility, power and validity of visual analogue scales in assessment of appetite sensations in single test meal studies. Int J Obes 24:38-48

34. Broom DR, Stensel DJ, Bishop NC, Burns SF, Miyashita M (2007) Exercise-induced suppression of acylated ghrelin in humans. J Appl Physiol 102(6):2165-2171

35. King JA, Deighton K, Broom DR, Wasse LK, Douglas JA, Burns $\mathrm{SF}$ et al (2017) Individual variation in hunger, energy intake, and ghrelin responses to acute exercise. Med Sci Sports Exerc 49(6):1219-1228

36. Deighton K, Karra E, Batterham RL, Stensel DJ (2013) Appetite, energy intake, and PYY 3-36 responses to energy-matched continuous exercise and submaximal high-intensity exercise. Appl Physiol Nutr Metab 38:947-952

37. Pradhan G, Samson SL, Sun Y (2013) Ghrelin: much more than a hunger hormone. Curr Opin Clin Nutr Metab Care 16(6):619-624

38. De Silva A, Bloom SR (2012) Gut hormones and appetite control: a focus on PYY and GLP-1 as therapeutic targets in obesity. Gut Liver 6(1):10-20

39. King JA, Wasse LK, Stensel DJ (2011) The acute effects of swimming on appetite, food intake, and plasma acylated ghrelin. J Obes 2011:1-8

40. Howe SM, Hand TM, Manore MM (2014) Exercise-trained men and women: role of exercise and diet on appetite and energy intake. Nutrients 6(11):4935-4960

41. Kawano H, Mineta M, Asaka M, Miyashita M, Numao S, Gando $Y$ et al (2013) Effects of different modes of exercise on appetite and appetite-regulating hormones. Appetite 66:26-33

42. Myers A, Dalton M, Gibbons C, Finlayson G, Blundell J (2019) Structured, aerobic exercise reduces fat mass and is partially compensated through energy intake but not energy expenditure in women. Physiol Behav 199:56-65

43. Church TS, Martin CK, Thompson AM, Earnest CP, Mikus CR, Blair SN (2009) Changes in weight, waist circumference and compensatory responses with different doses of exercise among sedentary, overweight postmenopausal women. PLoS ONE 4(2):e4515

44. Swift DL, Johannsen NM, Lavie CJ, Earnest CP, Church TS (2014) The role of exercise and physical activity in weight loss and maintenance. Prog Cardiovasc Dis 56(4):441-447

45. Jokisch E, Coletta A, Raynor HA (2012) Acute energy compensation and macronutrient intake following exercise in active and inactive males who are normal weight. Appetite 58(2):722-729

46. Mayer J, Thomas DW (1967) Regulation of food intake and obesity. Science 156(3773):328-337

47. Brunstrom JM (2005) Dietary learning in humans: directions for future research. Physiol Behav 85:57-65

48. Brunstrom JM, Shakeshaft NG (2009) Measuring affective (liking) and non-affective (expected satiety) determinants of portion size and food reward. Appetite 52(1):108-114

49. Fay S, Ferriday D, Hinton E, Shakeshaft N, Rogers P, Brunstrom J (2011) What determines real-world meal size? Evidence for premeal planning. Appetite 56:284-289

50. McCaig DC, Hawkins LA, Rogers PJ (2016) Licence to eat: information on energy expended during exercise affects subsequent energy intake. Appetite 1(107):323-329

51. Curioni CC, Lourenço PM (2005) Long-term weight loss after diet and exercise: a systematic review. Int J Obes 29(10):1168-1174

52. Thongworn S, Sirisuk V (2018) Weight control specific compensatory health beliefs: hypothetical testing and model extension. Kasetsart J Soc Sci 39(2):312-319

53. Rabiau M, Knäuper B, Miquelon P (2006) The eternal quest for optimal balance between maximizing pleasure and minimizing harm: the compensatory health beliefs model. Br J Health Psychol 11:139-153

54. Burke LM, Hawley JA, Wong SHS, Jeukendrup AE (2011) Carbohydrates for training and competition. J Sports Sci 29(Suppl. 1):17-27 